\title{
Comparative study of cardiac function between two populations in Latin America using the transthoracic echocardiogram: Atahualpa, Ecuador, and Mexico City, Mexico
}

\author{
Estudio comparativo de la función cardíaca en dos poblaciones de América Latina \\ mediante el ecocardiograma transtorácico: Atahualpa, Ecuador y Ciudad de México, \\ México
}

\begin{abstract}
Juan M. García-Graullera ${ }^{1}$, Juan A. Nader-Kawachi2*, Liliana Crespo-Serge', and Óscar H. del Brutto ${ }^{3}$
${ }^{1}$ Department of Echocardiography, Comprehensive Center for Diagnosis and Treatment; ${ }^{2}$ Neurology and Neurosurgery Unit, Cerebrovascular Disease Clinic, Hospital Médica Sur, Mexico City, Mexico; ${ }^{3}$ Medical School, Universidad Espíritu Santo, Samborondón, Ecuador
\end{abstract}

\begin{abstract}
Objective: The objective of the study was to compare morphological and functional differences of the heart in two Latin American populations with different ethnicity and living conditions. Methods: Using transthoracic echocardiogram, we obtained data on 206 individuals: 103 from Atahualpa, Ecuador (living at sea level, mean age: $75 \pm 4.2$ years, 53 women) and 103 inhabitants from Mexico City (living at 2,300 m above sea level, mean age: $75 \pm 4.2$ years, 52 women). Results: Significant differences between Atahualpa and Mexico were: Heart rate 66 versus 80 x', left ventricular diastolic diameter 40.8 versus 42.7, septum thickness 9.8 versus 11.6, posterior wall 10.2 versus 11.8 , stroke volume cc 53.0 versus 46.6 , left atrial volume 25. 8 versus 33.6, systolic pressure of the pulmonary artery 27.1 versus 42.0 , cardiac output 3.1 versus 4.8 , E/Ea ratio 6.4 versus 9.2, and mitral area 3.4 versus 3.0. Comparison of diastolic function between Atahualpa and Mexico was: Type 0; 2 versus 1, Type 1; 96 versus 81, Type 2; 5 versus 20, and Type 3; 0 versus 1. Conclusions: Echocardiographic characteristics that identify adaptive changes of the heart in Atahualpa are coincident with people living at sea level and with good physical activity, and Mexico City, with inhabitants living at high altitudes and exposed to environmental pollution. The systolic function of the left ventricle was similar in both populations, indicating that adaptive changes allow the heart to be effective in different circumstances of the ecosystem.
\end{abstract}

Key words: Transesophageal echocardiogram. Pulmonary hypertension. Hypoxemia. Latin America. High altitude. Environmental pollution.

\section{Resumen}

Objetivo: Comprobar las diferencias morfológicas y funcionales del corazón en dos poblaciones latinoamericanas con distintas características raciales y condiciones de vida. Métodos: Mediante el ecocardiograma transtorácico se obtuvieron datos de 206 personas: 103 del poblado de Atahualpa, Ecuador (nivel del mar, edad $\bar{x} 75 \pm 4.2$ años, 53 mujeres) y 103 habitantes de la Ciudad de México (altitud de 2,300 m, edad $\bar{x} 75 \pm 4.2$ años, 52 mujeres). Resultados: Las diferencias significativas

\section{Correspondence:}

*Juan A. Nader-Kawachi

E-mail: juan.nader.k@gmail.com license (http://creativecommons.org/licenses/by-nc-nd/4.0/).

Date of reception: 08-10-2019

Date of acceptance: 16-01-2020

DOI: 10.24875/ACME.M20000127
Available online: 04-12-2020 Arch Cardiol Mex (Eng). 2020;90(3):248-257 www.archivoscardiologia.com 
entre Atahualpa y la Ciudad de México fueron frecuencia cardíaca, 66 vs. 80; diámetro diastólico ventricular izquierdo, 40.8 vs. 42.7; grosor del tabique, 9.8 vs. 11.6; pared posterior, 10.2 vs. 11.8; volumen-latido en centímetros cúbicos, 53.0 vs. 46.6 ; volumen auricular Izquierdo, 25.8 vs. 33.6; presión sistólica de la arteria pulmonar, 27.1 vs. 42.0; gasto cardíaco, 3.1 vs. 4.8; cociente E/Ea, 6.4 vs. 9.2; área mitral, 3.4 vs. 3.0. El comparativo de la función diastólica entre Atahualpa y la Ciudad de México fue: tipo 0: 2 vs. 1; tipo 1: 96 vs. 81; tipo 2: 5 vs. 20; tipo 3: 0 vs. 1. Conclusión: Las características ecocardiográficas que identifican los cambios adaptativos del corazón en Atahualpa coinciden con personas que viven a nivel del mar y con buena actividad física y en México con los habitantes de grandes altitudes y expuestos a contaminación ambiental. La función sistólica del ventrículo izquierdo fue similar en ambas poblaciones, lo que indica que los cambios adaptativos hacen posible que el corazón sea eficaz en diferentes circunstancias del ecosistema.

Palabras clave: Ecocardiograma transesofágico. Hipertensión pulmonar. Hipoxemia. América Latina. Gran altitud. Contaminación ambiental.

\section{Introduction}

In the last decade, knowledge about non-communicable neurological diseases epidemiology, particularly cardiovascular and cerebrovascular conditions in Latin America, has increased thanks to epidemiological studies in different areas of the region ${ }^{1-5}$. There is growing interest in analyzing the physiological, pathological, and epidemiological differences between different ethnic groups and people with diverse lifestyles. At present, more than 140 million people are known to live in places at 2,500 m above sea level and many more move for recreation or due the constant migration of populations, forcing their bodies to adapt to the new habitat ${ }^{6}$.

Studies comparing and demonstrating the physiological characteristics of the heart in different ethnic groups $^{7}$ that live in different habitats and altitudes have been conducted 8 .

The racial and genetic characteristics of the Atahualpa population, as well as the definitions and methodology of the Atahualpa Project, have been previously described ${ }^{9}$. On the other hand, Médica Sur Hospital is located in an urban milieu of the southern area of Mexico City, with a wide area of influence and whose inhabitants have varying degrees of miscegenation and live at an average altitude of 2,240 m.

Joint efforts between the Atahualpa Project and Médica Sur Hospital Neurology Department researchers have enabled the performance of collaborative studies that demonstrate the variability of the phenotypic and physiological characteristics between two markedly different Latin American populations ${ }^{10}$. According to the above, this work, which uses transthoracic echocardiogram (TT-ECHO), aims to confirm the hypothesis that there are anatomical and heart functional differences in two populations with different habits, places of residence and racial characteristics and that, in addition, live in settlements with different altitudes with regard to sea level and varying degrees of exposure to environmental pollutants.

\section{Objective}

This is a cross-sectional, observational study with an analytical design aimed at exploring and contrasting the differences (hypothesis testing) of the quantitative and qualitative $\mathrm{ECHO}$ variables in two populations with clearly different genetic makeup, habitat, and anthropometric characteristics.

\section{Subjects and methods}

\section{Selection criteria}

In Ecuador, 103 people from the Atahualpa Civil Parish (municipality), which corresponds to $25 \%$ of the population included in the entire sample of the Atahualpa Project, were randomly chosen ${ }^{9}$. The only exclusion criterion was the expressed will not to participate in the study. To perform a comparative analysis, in Mexico City, 103 apparently healthy consecutive patients, who attended the Médica Sur Hospital Diagnosis and Treatment Clinic to undergo a systematic evaluation of their health status, without there being any confirmed illness at time of the visit, were selected. The patients were consecutively selected and matched in terms of age and gender with respect to the Atahualpa population.

\section{Description of habitat and study populations}

The Atahualpa Civil Parish is located at the Ecuadorian coast at sea level and is constituted, from a racial point of view, of Native South Americans with scarce emigration and a relatively common lineage. Almost all 
are woodworkers and their food comes essentially from the sea in the form of daily fishing. Both men and women have an acceptable degree of physical activity in their daily lives.

The population that attends the Médica Sur Hospital comprehensive diagnostic center comes from different sectors of Mexico City at an altitude that ranges between 2,200 and 2,400 m above sea level. Ethnicity of these individuals is diverse, mostly with variable degrees of miscegenation between Native Americans of the Mexican highlands and Europeans (predominantly from Spain) and from the rest of the world. Work activity of these subjects is of the bureaucratic type with little physical activity and a diverse diet, including processed foods.

\section{Statistical methodology}

The Kolmogorov-Smirnov test was used to determine the normality in the distribution of data. To establish and analyze the difference between continuous variables between groups, the $\mathrm{T}$ - and Z-tests were used, with a 95\% confidence interval. To support the hypothesis that TT-ECHO differences allow describing the characteristics between both populations, a logistic-regression test was used.

\section{TT-ECHO methodology}

The patients underwent a standard TT-ECHO examination ${ }^{11}$. In Atahualpa, a Terason Usmart 3300 portable echocardiograph (Boston, MA, USA) was used and, in Mexico City, a Phillips echocardiograph, model IE33 and HD15 (The Netherlands). In all cases, indexed values were used to adjust for anthropometric variability between both samples. All the studies were carried out by the same two experts (JMGG and LCS), thus avoiding inter-operator and inter-observer variability.

Obtaining quantitative, qualitative, anatomical, and functional data of the heart were possible through M-mode, two-dimensional mode color, continuous, pulsed and tissue Doppler, according to the American Society of Echocardiography ${ }^{12}$ criteria, as follows:

Parasternal long axis: Quantitative measures: left ventricle size; ventricular walls thickness, left atrium diameter and cortical root; and left ventricular outflow tract diameter.

Short axis at the apex level: Qualitative measurements: papillary and mitral valve muscles description, with its mobility being assessed at all 17 conventional segments. The result was descriptive, and for statistical purposes, it was dichotomized (normal vs. abnormal).

Four-chamber apical axis: quantitative measurements: diameter and volume of both atria were evaluated in two dimensions, and right ventricle diameter. Qualitative measurements: left ventricular mobility at its lateral wall and of the septum at its lower portion.

Two-chamber apical: qualitative measures: left ventricle inferior wall and anterior wall mobility.

Three-chamber apical: qualitative measures: posterolateral wall and septum anterior portion mobility.

Valve evaluation: qualitative measurements by means of different takes with two-dimensional mode for morphological analysis. Color Doppler to assess valve insufficiencies, pulsed Doppler to evaluate normal velocities and gradients, continuous Doppler to assess velocities, and gradients above normal limits. The mitral valve area is measured by hemipressure time.

Diastolic function was assessed based on the 2015 guidelines ${ }^{11}$ with pulsed Doppler at the level of the left ventricle inlet pathway, with measurement of $\mathrm{E}$ - and A-waves, and the relationship between both; and tissue Doppler to measure lateral $E$ prime wave to obtain left ventricular end-diastolic pressure, which in most cases are the relationship of the ratio of mitral E-wave peak velocity and mitral lateral annulus E-velocity (E/Ea).

Based on the obtained measurements, the diastolic function was classified in the following categories: type $0=$ normal; type 1 = slow relaxation; type 2 = pseudonormal; and type $3=$ restrictive $^{13}$. Pulmonary pressure measurement was performed by calculating the tricuspid insufficiency gradient and the sum of the left atrial pressure (Bernoulli equation) ${ }^{14}$.

The left ventricle function was determined by means of the left ventricular ejection fraction (LVEF) using fourand two-chamber approaches on the apical axis. The Simpson biplane method was used. The right ventricle function was calculated using the M-mode at the level of the tricuspid valve to detect tricuspid annular plane systolic excursion (TAPSE).

The stroke volume (SV) in cubic centimeters was obtained by measuring the aortic velocity-time integral through the area of the left ventricle outflow tract. Cardiac output (CO) was extracted by multiplying this value by the heart rate $(\mathrm{HR})^{11}$.

\section{Results}

A total of 206 subjects were studied: 103 in Atahualpa (53 women and 50 men), with a mean age of $75.2 \pm$ 
Table 1. Population comparison: demographics

\begin{tabular}{|l|c|c|}
\hline Gender & $\begin{array}{c}\text { Atahualpa } \mathbf{n}=\mathbf{1 0 3} \\
\mathbf{n}(\%)\end{array}$ & $\begin{array}{c}\text { Mexico City } \mathbf{n}=\mathbf{1 0 3} \\
\mathbf{n}(\%)\end{array}$ \\
\hline Females & $53(51)$ & $52(50)$ \\
\hline Males & $50(49)$ & $51(50)$ \\
\hline Age & Average max/min-DT & Average max/min-DT \\
\hline All & 75.2 & 75.2 \\
\hline Females & $95 / 62-8.4$ & $94 / 59-8.4$ \\
\hline Males & 75.7 & 75.7 \\
& $94 / 62-8.4$ & $94 / 61-8.3$ \\
\hline
\end{tabular}

Table 2. Population comparison: anthropometry

\begin{tabular}{|l|c|c|}
\hline Anthropometry & $\begin{array}{c}\text { Atahualpa } \\
\text { Average } \\
\text { max/min.-SD }\end{array}$ & $\begin{array}{c}\text { Mexico City } \\
\text { Average } \\
\text { max/min.-SD }\end{array}$ \\
\hline Weight, $\mathrm{kg}$ & $\begin{array}{c}57 \\
84 / 32-10.2\end{array}$ & $\begin{array}{c}71 \\
187 / 157-7.4\end{array}$ \\
\hline Height, cm & 148.7 & 162.4 \\
\hline Body surface area, $\mathrm{m}^{2}$ & $168 / 133-9.0$ & $187 / 140-9.6$ \\
\hline & 1.49 & 1.76 \\
\hline
\end{tabular}

4.2 years, and 103 in Mexico City (52 women and 51 men), with a mean age of $74.8 \pm 4.2$ years (Table 1 ).

\section{Demographic data}

Socio-demographic characteristics: Atahualpa is located at sea level, with moderate to intense physical activity of its population and homogeneous ethnicity (Amerindians) and no pollution. Mexico City is at an altitude of $2300 \mathrm{~m}$ above sea level, with little to moderate physical activity and diverse ethnicity of its population, who are exposed to different pollutants.

Anthropometry: the population of Mexico were on average taller $(162.4 \mathrm{~cm}$ vs. $148.7 \mathrm{~cm}$ ), had higher body weight $(71 \mathrm{~kg}$ vs. $57 \mathrm{~kg}$ ), and larger body surface area, according to the Dubois and Dobois method $\left(1.76 \mathrm{~m}^{2}\right.$ vs. $1.49 \mathrm{~m}^{2}$ ), $\mathrm{p}<0.05$ (Table 2).

Cardiovascular risk factors: no differences were observed in the number of people who suffered from diabetes mellitus (DM), high blood pressure (HBP), and dyslipidemia; in contrast, smoking was recorded in 12 subjects of the Mexican population and only in one
Table 3. Population comparison: cardiovascular risk factors

\begin{tabular}{|l|c|c|}
\hline Risk factors & Atahualpa n (\%) & Mexico City n (\%) \\
\hline Diabetes mellitus & $31(30)$ & $24(23)$ \\
\hline Hypertension & $51(50)$ & $49(48)$ \\
\hline Dyslipidemia & $15(15)$ & $20(19)$ \\
\hline Smoking & $1(1)$ & $12(12), \mathrm{p}<001$ \\
\hline CVD & $18(17)$ & $4(4), \mathrm{p}<001$ \\
\hline
\end{tabular}

case in Atahualpa. Previous history of cerebral vascular events was identified in 18 subjects in Atahualpa and in four in Mexico City (Table 3).

\section{TT-ECHO variables}

When the populations of Atahualpa and Mexico City were compared, the following parameters were found, respectively: HR, 67 versus $80(p=0.02)$; left ventricular diastolic diameter (LVDD), 40.8 versus 42.7 $(p<0.05)$; left ventricular systolic diameter (LVSD), 26.0 versus 26.2; LV septum thickness, 9.8 versus 11.6 $(p<0.001)$; posterior wall (PW) thickness, 10.2 versus 11.8 ( $p<0.005)$; LVEF, 65.3 versus 65.1; TAPSE, 20.1 versus 20.03; SV, 53.0 versus $46.6(p<0.005)$; left atrium volume, 25.8 versus $33.6(p<0.005)$; pulmonary artery systolic pressure (PASP), 27.1 versus 42.0 $(p<0.005)$; CO, 3.1 versus 4.8 ( $p<0.005)$; mass, 92.6 versus 99.4; end-diastolic pressure ratio (E/Ea), 6.4 versus $9.2(p<0.005)$; aortic area, 2.1 versus 2.2 ; and mitral area, 3.4 versus $3.0(p<0.005)$ (Table 4).

Diastolic function: Atahualpa: two individuals with normal diastolic function, 96 with type 1 diastolic dysfunction and five with type 2 diastolic dysfunction; Mexico City: one with normal diastolic function, 81 with type 1 diastolic dysfunction, 20 with type 2 diastolic dysfunction $(p<0.05)$, and one with type 3 diastolic dysfunction (Table 5).

When the difference in the number of people with the smoking habit and cerebrovascular disease (CVD) between the two study populations was considered, the statistical analysis where the people with said characteristics and their respective comparative matches were excluded was carried out separately. In this sub-analysis, only the difference in SV was found to be slightly lower (when patients with CVD were excluded), but it maintained a statistically significant difference $(p=0.001-0.016)$. In no other 
Table 4. Transthoracic echocardiogram results comparison

\begin{tabular}{|c|c|c|c|c|}
\hline Variable & Atahualpa Average max/min-SD & Mexico City Average max/min-SD & p-value & p-value without smoking \\
\hline LVDD & $\begin{array}{c}40.8 \\
58 / 27-5.4\end{array}$ & $\begin{array}{c}42.7 \\
61 / 26-4.4\end{array}$ & 0.006 & 0.005 \\
\hline LVSD & $\begin{array}{c}26.0 \\
49 / 16-5.4\end{array}$ & $\begin{array}{c}26.2 \\
47 / 15-5\end{array}$ & 0.787 & 0.691 \\
\hline Septum & $\begin{array}{c}9.8 \\
15 / 6-1.6\end{array}$ & $\begin{array}{c}11.6 \\
18 / 7-1.9\end{array}$ & $<0.0001$ & $<0.0001$ \\
\hline PW & $\begin{array}{c}10.2 \\
15 / 6-1.5\end{array}$ & $\begin{array}{c}11.8 \\
35 / 7-2.9\end{array}$ & $<0.0001$ & $<0.0001$ \\
\hline LVEF & $\begin{array}{c}64.3 \\
73 / 35-7.3\end{array}$ & $\begin{array}{c}65.1 \\
81 / 25-8.8\end{array}$ & 0.503 & 0.501 \\
\hline TAPSE & $\begin{array}{c}20.1 \\
29 / 14-2.9\end{array}$ & $\begin{array}{c}20.3 \\
32 / 12-3.6\end{array}$ & 0.732 & 0.775 \\
\hline SV & $\begin{array}{c}53.0 \\
88.5 / 28.8-13\end{array}$ & $\begin{array}{c}46.6 \\
86 / 20.8-16.7\end{array}$ & 0.003 & 0.001 \\
\hline LAV & $\begin{array}{c}25.8 \\
73.6 / 11.1-8.6\end{array}$ & $\begin{array}{c}33.6 \\
95 / 12.9-12.9\end{array}$ & $<0.0001$ & $<0.0001$ \\
\hline PASP & $\begin{array}{c}27.1 \\
42 / 18-4.8\end{array}$ & $\begin{array}{c}42.0 \\
83 / 14-10.6\end{array}$ & $<0.0001$ & $<0.0001$ \\
\hline $\mathrm{CO}$ & $\begin{array}{c}3.1 \\
10.2 / 1.4-1.1\end{array}$ & $\begin{array}{c}4.8 \\
9.9 / 2.2-1.4\end{array}$ & $<0.0001$ & $<0.0001$ \\
\hline Mass & $\begin{array}{c}92.6 \\
202 / 47.8-24.4\end{array}$ & $\begin{array}{c}99.4 \\
219 / 38.9-30.9\end{array}$ & 0.080 & 0.067 \\
\hline $\mathrm{E} / \mathrm{Ea}$ & $\begin{array}{c}6.4 \\
16.3 / 3.1-2.1\end{array}$ & $\begin{array}{c}9.2 \\
30.8 / 2.8-4.3\end{array}$ & $<0.0001$ & $<0.0001$ \\
\hline$A A$ & $\begin{array}{c}2.1 \\
4.7 / 0.8-0.6\end{array}$ & $\begin{array}{c}2.2 \\
4.8 / 1-0.7\end{array}$ & 0.337 & 0.343 \\
\hline MA & $\begin{array}{c}3.4 \\
7.2 / 1.5-0.95 .4\end{array}$ & $\begin{array}{c}3.0 \\
6.7 / 1.3-1.01 .6\end{array}$ & 0.002 & 0.002 \\
\hline HR & $\begin{array}{c}67 \\
201 / 19-30.3\end{array}$ & $\begin{array}{c}80 \\
188 / 20-35.1\end{array}$ & 0.002 & 0.003 \\
\hline
\end{tabular}

AA: aortic area; CO: cardiac output; E/Ea: end-diastolic pressure ratio; HR: heart rate; LAV: left atrium volume; LVDD: left ventricular diastolic diameter; LVEF, left ventricular ejection fraction; LVSD, left ventricular systolic diameter; MA: mitral area; mass: left ventricle mass, grams per square meter; PASP: pulmonary artery systolic pressure; PW: posterior wall thickness; Septum: interventricular septum thickness; SV: stroke volume in cubic centimeters; TAPSE: tricuspid annular plane systolic excursion.

case was the difference in TT-ECHO variables modified (Table 5).

When the two populations were compared by means of echocardiogram interpretive analysis, two patients in the Atahualpa sample were found with a lesion consistent with myocardial infarction, while in Mexico City 7 individuals had some visible structural damage, distributed as follows: myocardial infarction (1), hypokinetic segments (3), mitral valve disease (1), tricuspid valve disease (1), and congestive heart failure (1).

While the comparative analysis allowed establishing the hypothesis according to which there is a difference between the TT-ECHO variables, and that it can distinguish the populations of one and the other place, the logistic regression analysis allowed to confirm it by establishing the variables' weight. Figure 1 shows the standardized coefficients resulting from the logistic regression. Therein, by means of the sign direction (positive or negative), the behavior of each one of the variables related to the condition of living in Atahualpa (below 0) or in Mexico City (above 0) can be distinguished. This way, the septum, PASP, E/Ea, and aortic area variables statistically significantly distinguish $90 \%$ of Mexico City inhabitants, as well as the LVDD and $\mathrm{CO}$ variables, but with less statistical power. On the 


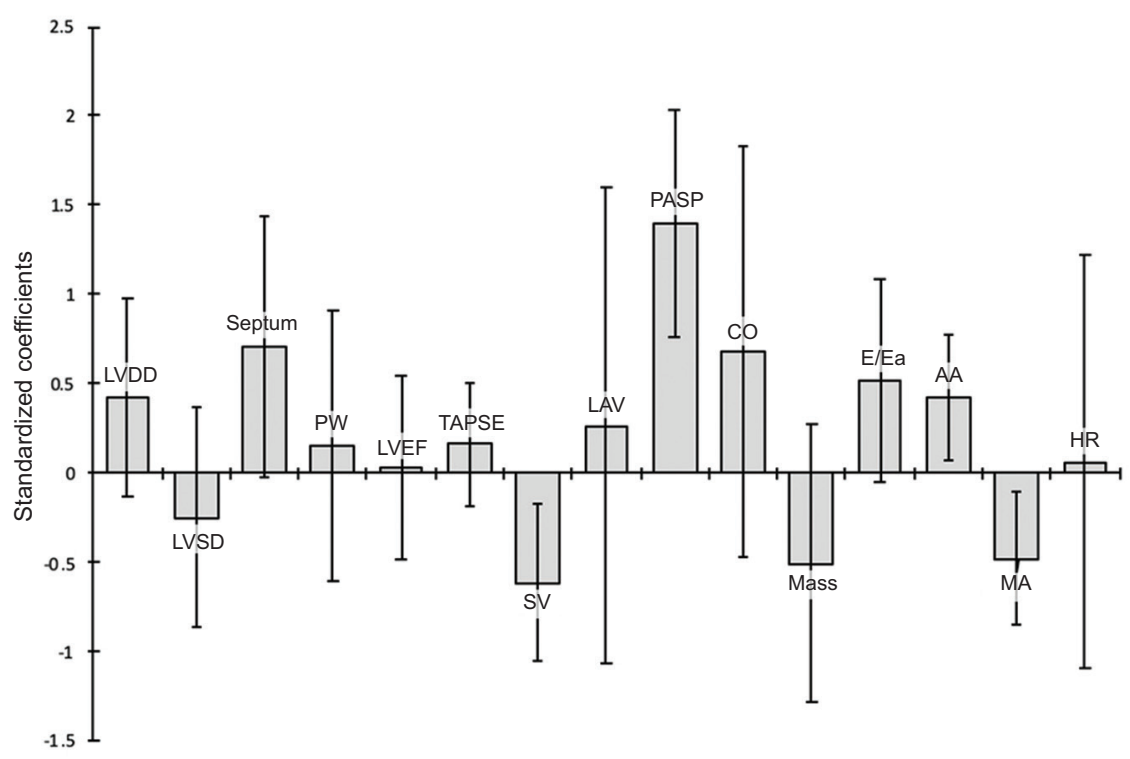

Figure 1. Logistic regression standardized coefficients using the habitat and the echocardiogram dependent variables as explanatory variable (95\% confidence interval). AA: aortic area; $\mathrm{CO}$ : cardiac output; E/Ea: end-diastolic pressure ratio; HR: heart rate; LAV: left atrium volume; LVDD: left ventricular diastolic diameter; LVEF: left ventricular ejection fraction; LVSD: left ventricular systolic diameter; MA: mitral area; Mass: left ventricle mass, grams per square meter; PASP: pulmonary artery systolic pressure; PW: posterior wall thickness; Septum: interventricular septum thickness; SV: stroke volume in cubic centimeters; TAPSE: tricuspid annular plane systolic excursion.

Table 5. Type of diastolic function

\begin{tabular}{|l|l|c|c|}
\hline & & Atahualpa & Mexico City \\
\hline Type 0 & Normal & 2 & 1 \\
\hline Type 1 & Slow relaxation & 96 & $\begin{array}{c}81 \\
\mathrm{p}<0.05\end{array}$ \\
\hline Type 2 & Pseudonormal & 5 & $\begin{array}{c}20 \\
\mathrm{p}<0.05\end{array}$ \\
\hline Type 3 & Restrictive & 0 & 1 \\
\hline & Total & 103 & 103 \\
\hline
\end{tabular}

other hand, SV and mitral area statistically significantly distinguish the Atahualpa inhabitants, and the left ventricular mass variable, despite being distinctive of this population in $80 \%$ of cases, did not reach statistical significance. When all variables were jointly considered by means of a ROC analysis, these differences had an area under the curve of 0.975 . In the logistic regression, HBP, DM, and smoking did not have a causal relationship that explains by itself the changes on TT-ECHO.

\section{Discussion}

Human beings have adapted themselves to the environment through a long evolutionary process that enables their survival. In recent decades, increasing urbanization of rural communities and frequent migration of people produce lifestyle changes that require a much faster adaptation and produce diverse reactions from the molecular level up to an integrative organic level ${ }^{15}$.

Latin America is one of the regions of the world with greater genetic, customary, and habitat diversity. The comparative analysis of these data confirmed the hypothesis that there are anatomical and physiological differences in the hearts of Atahualpa and Mexico City inhabitants and that these are due to different adaptive factors.

\section{Ethnic and demographic factors}

Differences in height and body weight, physical activity, and cardiovascular risk factors have an influence on cardiac function ${ }^{16}$. Since there is a direct relationship between height and left ventricle mass, given the 
shorter stature of the Atahualpa population, it is expected for these individuals to have a lower left ventricular mass. To homogenize the sample, the ECHO indexed values were used in all cases. In the population of Atahualpa, the left ventricle contractile efficiency is demonstrated with a higher SV, and this allows to maintain an effective $\mathrm{CO}$ even with lower HRs. These findings illustrate that the importance lifestyle has on ventricular function, as it occurs in people with higher physical activity, such as high-performance athletes ${ }^{17}$; at Atahualpa, the relationship between left ventricle mass, SV, and $\mathrm{CO}$ describes the efficacy of ventricular contractility to maintain $\mathrm{CO}$ with a low HR. Conversely, with height, and in particular body weight, being $\mathrm{CO}$ conditional determinants in Mexico City inhabitants, it can be inferred that these are the consequence of the urban and sedentary life in this population (Fig. 1).

An interesting difference between bot populations is IV septum thickness. This difference cannot be attributed to ethnic diversity itself. In a study of 1818 inhabitants of the Latino community in USA urban areas, there were no differences in IV septum or PW, except in people of Cuban and Caribbean origin, with African genetic makeup 7,18 . Other factors that influence on septum thickness are $\mathrm{HBP}^{19}$, smoking ${ }^{20}$, and obesity ${ }^{16}$. For example, HBP causes left ventricle and IV septum remodeling ${ }^{19}$. In the studied populations, it was not possible to determine the influence of HBP on septum thickness, given that its prevalence was similar. Conversely to the above, smoking was more prevalent in Mexico City residents. To understand the influence of smoking on TT-ECHO variables, a statistical test was carried out to compare only non-smokers in both groups and, although the populations were more similar, the difference was observed to still be statistically significant; that is, in addition to smoking, there are other factors that influence on septum thickness. Regarding obesity, as already mentioned, body surface area in Mexico City was larger than in Atahualpa. TT-ECHO changes with overweight include septum thickening, even when considering that, in many obese patients, ventricular remodeling is eccentric, and in this series concentric remodeling predominated ${ }^{16}$.

\section{Hypoxemia and altitude}

The difference in barometric pressure between the sea level and $2500 \mathrm{~m}$ above sea level reduces $\mathrm{O}_{2}$ pressure by between 20 and $30 \%$. This means that a person who lives at sea level is exposed to an $\mathrm{O}_{2}$ inspired fraction ranging from 21 to $14 \%{ }^{21}$. In other words, in
Mexico City, there is $20-30 \%$ less oxygen available in the air than in Atahualpa.

Various studies have investigated populations that reside in altitudes higher than $3000 \mathrm{~m}$ above sea level, but there are far fewer that consider the immense population living in intermediate altitudes, between 2000 and $3000 \mathrm{~m}$ above sea level. Only in the Mexican Republic, around 30 million people live in altitudes higher than $2000 \mathrm{~m}$ above sea level, and $90 \%$ of them correspond to urban settlements that have received migration from lower-altitude rural areas ${ }^{22}$. In high-altitude dwellers, the first adaptive mechanism to hypoxia is $\mathrm{HR}$ increase $^{23}$ and SV decrease ${ }^{24}$. The authors found a higher HR (80 vs. $67, p<0.002)$ and lower SV (53.0 vs. 46.6, $p<0.005$ ) in Mexico City versus Atahualpa residents. These phenomena are mediated by an increase in sympathetic activity. Healthy people who are exposed to extreme heights have been shown to have higher plasma noradrenaline concentration ${ }^{25}$. In a recent study of healthy volunteers progressively exposed to hypoxia when moving to places with higher altitude, elevated noradrenaline plasma values were recorded at the time they migrated to a higher altitude and still continued even after an adaptive period of 4 weeks ${ }^{26}$. An inverse phenomenon is also known to occur when an inhabitant of heights moves from an elevated place to sea level24.

Since pulmonary pressure is a low pressure system, small increases in right ventricular output resistance translate into considerable physiological alterations. Under conditions of altitude, in addition to a low $\mathrm{O}_{2}$ concentration and a decrease in body water volume ${ }^{8}$, hematocrit increases and, due to vasoconstriction of the pulmonary arteries, there is an increase in pulmonary circulation afterload resistance ${ }^{27}$. Patients who normally reside at altitudes higher than $2000 \mathrm{~m}$ above sea level, show a persistent state of pulmonary hypertension ${ }^{28}$. This state produces remodeling of the pulmonary arteries and arterioles due to hypertrophy and hyperplasia of the muscle layer and decreased vascular lumen ${ }^{28,29}$. In the logic of living beings' adaptive processes, exposure to different environmental situations induces changes that ultimately cause transcriptional modifications. Recently, the hypoxia-induced factor pathway has been described in residents of high altitudes; this line of knowledge offers a new explanation that allows understanding adaptive changes of the heart in the long term ${ }^{6}$. In coincidence with the above, the obtained data point at PASP as the functional comparative that most distinguishes the studied populations; PASP in Atahualpa was 27.1 and in Mexico City 
it was 42.0 , which reveals a state of persistent pulmonary hypertension in the latter population. In the logistic regression test, PASP turned out to be the highest causality indicator between altitude and habitat conditions. In this regard, in 2003, the WHO included hypoxemia caused by prolonged exposure to high altitude as a cause related to pulmonary hypertension within Group $1 \mathrm{II}^{30}$. The characteristic of this group is that it is mostly physiological conditions that can change when the causative factor is modified.

In Mexico City residents, septum thickness and left ventricular PW thickness due to ventricular wall concentric remodeling were larger. In this regard, a TTECHO study in high-altitude inhabitants demonstrates IV septum lower mobility of and LV posterolateral wall higher mobility and contractile efficiency, which makes it possible to maintain an adequate ejection fraction under high altitude conditions ${ }^{23}$. On the other hand, in a comparative study between great-altitude frequent inhabitants (Sherpas), high-altitude recently adapted inhabitants, and sea-level inhabitants, a lower IV septum thickness was documented both in Sherpas and in those adapted to high altitudes ${ }^{8}$. Although these changes appear not to be significant, they are opposed to the findings herein presented.

Interestingly, despite the already-described functional and morphological differences of the heart, no significant differences were observed in LVSD or TAPSE, which shows that systolic function normalization is the ultimate mechanism that gives rise to adaptation to different altitude circumstances ${ }^{8}$.

\section{Environmental pollution}

It has been estimated that 4.2 million of premature deaths in the world are due to conditions related to environmental pollution; out of these, $36 \%$ are the consequence of lung disease; $34 \%$, of stroke; and $27 \%$, of any cardiac complication ${ }^{31}$. Moreover, pollution causes serious brain consequences ${ }^{32}$, including Alzheimer's disease ${ }^{33}$. There are relatively few works looking into the effects of environmental pollution on the heart and, in the authors' opinion, no one compares populations that live in extreme conditions in terms of air quality. In this work, this difference is quite evident; while in Atahualpa there is little or no air pollution produced by industrial activities or internal combustion vehicles, in Mexico City these factors are determining causes of pollution.

In recent years, $\mathrm{CO}_{2}$ concentration has been relatively held back in Mexico City; however, other pollutants such as sulfur dioxide, ozone, and PM10- and PM2.5-type suspended particles exceed the values recommended by the $\mathrm{WHO}$ on $50 \%$ of days of the year ${ }^{34}$.

In the last decade, the influence urban stress has on diastolic dysfunction in young people ${ }^{35}$, probably mediated by brain natriuretic peptide ${ }^{36}$, as well as in older women exposed to environmental pollution due to exposure to ozone and PM2.5 and PM10 particles, has been described ${ }^{37}$. Accordingly, although it is true that, given the mean age of this population, it is expected that there will be some diastolic dysfunction in most subjects, the type of diastolic dysfunction was more severe in Mexico City. Ninety-six percent of people in Atahualpa, in comparison with $81 \%$ in Mexico City, were observed to experience diastolic dysfunction with a slow relaxation pattern (type 1), while diastolic dysfunction with pseudonormal pattern (type 2) was present in 5 in Atahualpa and 20 in Mexico City, with the differences being statistically significant (Table 5 ).

As already mentioned, left ventricular mass in Mexico City inhabitants was higher in relation to different factors. In a recent study ${ }^{38}$, constant exposure to PM2.5 fine particles and nitrogen dioxide was shown to generate phenotypic changes such as left ventricular mass and ventricular volume increase. In addition, exposure to noise and traffic produces phenotypic alterations that increase ventricular volume ${ }^{38}$. In this work, LVDD was higher in Mexico City residents, which indirectly indicates that in this population there is a larger ventricular volume, related, among other factors, to exposure to pollutants. In this investigation, ventricular volume was not included as a variable, which forces the conduction of a future work addressing this particular point.

\section{Conclusions}

The variables that characterize adaptive changes on TT-ECHO in both study populations were the following: Atahualpa: SV, left ventricle mass and mitral area; Mexico City: LVDD, septum, PASP, CO, E/Ea ratio, and aortic area.

Adaptive changes to different environmental conditions, especially hypoxia, occur in all people, regardless of ethnic group. These changes are caused by pulmonary systolic pressure elevation and right ventricular remodeling due to right chambers hypertrophy or slight dilation and less evident left ventricular changes. In this work, despite having a limited number of study subjects, the comparative methodology allowed to identify ECHO statistically significant differences between both populations. In this group, the people from Atahualpa had 
smaller ventricles with good mobility, an effect of living at sea level and of more intense physical activity; in contrast, Mexico City inhabitants had ventricular walls greater thickness, left atrial dilation secondary to ventricular remodeling and diastolic dysfunction, secondary to both altitude and urban lifestyle, and most likely related to environmental pollution; and the latter, according to the previous postulates, should therefore be considered as a modifiable cardiovascular risk factor.

\section{Key points}

- Change of habitat and living conditions produce adaptive changes in the heart.

- These changes, although related to individual genetic makeup, are influenced by altitude, physical activity and environmental pollution.

- In Latin America there is a high migratory rate from the countryside to the city.

- This work compares the heart echocardiographic characteristics of two Latin American populations that are genetically diverse and exposed to completely different environmental conditions.

- The Atahualpa inhabitants had smaller ventricles with good mobility, typical of sea-level settlers with intense physical activity.

- Mexico City inhabitants showed ventricular walls greater thickness, left atrial dilation, and diastolic dysfunction, which are inherent to inhabitants of high-altitude places, with an urban lifestyle and exposure to pollutants.

- These changes also describe the adaptation that is necessarily suffered by the large number of individuals who migrate to the cities.

- The influence of environmental pollution on the human body should motivate further investigations, either by this group or by other interested groups.

\section{Conflict of interests}

None.

\section{Funding sources}

This work was sponsored by Universidad Espíritu Santo, Samborondón, Ecuador. Other resources were provided by Servicios al Paciente Neurológico A.C., Mexico City, Mexico. None of the authors received any economic remuneration.

\section{Ethical disclosures}

Protection of human and animal subjects. The authors declare that no experiments were performed on humans or animals for this research.

Confidentiality of data. The authors declare that they have followed the protocols of their work center on the publication of patient data.

Right to privacy and informed consent. The authors have obtained informed consent from the patients and/or subjects referred to in the article. This document is in the possession of the corresponding author.

\section{References}

1. Saposnik G, Del Brutto $\mathrm{OH}$. Stroke in South America: a systematic review of incidence, prevalence, and stroke subtypes. Stroke. 2003;34: 2103-2107.

2. Lavados PM, Sacks C, Prina L, Escobar A, Tossi C, Araya F, Feuerhake W, et al. Incidence,30-daycase-fatalityrate, and prognosis of stroke in Iquique, Chile: a 2-year community-based prospective study (PISCIS Project). Lancet. 2005;365:2206-2215.

3. Medina MT, Thompson-Cerna AR. Prevalencia de la enfermedad cerebrovascular en la comunidad rural de Salamá, Honduras, utilizando el método epidemiológico de captura-recaptura. Rev Neurol. 2007;44: 460-464.

4. Cantú-Brito C, Majersik J, Sánchez B. Door-to-door capture of incident and prevalent stroke cases in Durango, Mexico: the brain attack surveillance in Durango Study. Stroke. 2011;42;3:601-606.

5. Lavados PM, Hennis AJM, Fernandes JG, Medina MT, Legetic B, Hoppe A, et al. Stroke epidemiology, prevention, and management strategies at a regional level: Latin America and the Caribbean. Lancet Neurol. 2007;6:362-372.

6. Bigham AW, Lee FS. Human high-altitude adaptation: forward genetics meets the HIF pathway. Genes Dev. 2014;28:2189-2204.

7. Qureshi WT, Leigh JA, Swett K, Dharod A, Allison MA, Cai J, et al. Comparison of echocardiographic measures in a hispanic/latino population with the 2005 and 2015 American society of echocardiography reference limits (The Echocardiographic Study of Latinos). Circ Cardiovasc Imaging. 2016;9:1-9.

8. Stembridge M, Ainslie PN, Hughes MG, Stöhr EJ, Cotter JD, Nio AQ, et al. Ventricular structure, function, and mechanics at high altitude: chronic remodeling in Sherpa vs. short-term lowlander adaptation. J Appl Physiol. 2014;117:334-343.

9. Del Brutto OH, Peñaherrera E, Ochoa E, Santamaría M, Zambrano M, Del Brutto VJ; Atahualpa Project Investigators. Door-to-door survey of cardiovascular health, stroke, and ischemic heart disease in rural coastal Ecuador - the Atahualpa Project: methodology and operational definitions. Int J Stroke. 2014;9:367-371.

10. Nader JA, Andrade ML, Espinosa V, Zambrano M, Del Brutto O. H. Technical difficulties due to poor acoustic insonation during transcranial doppler recordings in Amerindians and individuals of European origin. A comparative study. European Neurology. 2015;73:230-232.

11. Lang RM, Badano LP, Mor-Avi V, Afilalo J, Armstrong A, Ernande L, et al. Recommendations for cardiac chamber quantification by echocardiography in adults: an update from the American Society of Echocardiography and the European Association of Cardiovascular Imaging. J Am Soc Echocardiogr. 2015;28(1):1-39.e14.

12. Mitchell C, Rahko PS, Blauwet LA, Canaday B, Finstuen JA, Foster MC, et al. Guidelines for performing a comprehensive transthoracic echocardiographic examination in adults: recommendations from the American Society of Echocardiography. J Am Soc Echocardiogr. 2019;32:1-64.

13. García MJ. Diagnóstico y guía terapéutica de la insuficiencia cardiaca diastólica. Rev Esp Cardiol. 2003;56:396-406.

14. Galiè N, Humbert M, Vachiery JL, Gibbs S, Lang I, Torbicki A, et al. ESC Scientific Document Group. 2015 ESC/ERS Guidelines for the diagnosis and treatment of pulmonary hypertension: The Joint Task Force for the Diagnosis and Treatment of Pulmonary Hypertension of the European Society of Cardiology (ESC) and the European Respiratory Society (ERS): Endorsed by: Association for European Paediatric and Congenital Cardiology (AEPC), International Society for Heart and Lung Transplantation (ISHLT). Eur Heart J. 2016;37:67-119.

15. International Migration Database. OECD Statistics. https://stats.oecd.org/ Index.aspx?DataSetCode=MIG Consultado el 20 de junio de 2019. 
16. Alpert MA, Terry BE, Mulekar M, Cohen MV, Massey CV, Fan TM, et al. Cardiac morphology and left ventricular function in normotensive morbidly obese patients with and without congestive heart failure, and effect of weight loss. Am J Cardiol. 1997;80:736-740.

17. Fagard R. Athlete's heart. Heart. 2003;89:1455-1461.

18. Rodríguez CJ, Dharod A, Allison MA, Shah SJ, Hurwitz B, Bangdiwala SI, et al. Rationale and design of the echocardiographic study of hispanics/ latinos (ECHO-SOL). Ethn Dis. 2015;25:180-186.

19. Aronow WS. Hypertension and left ventricular hypertrophy. Ann Trans Med. 2017;5:310

20. Eroglu E, Aydin S, Yalniz F, Kalkan AK, Bayrak F, Degertekin M. Chronic cigarette smoking affects left and right ventricular long-axis function in healthy young subjects: a Doppler myocardial imaging study. Echocardiography. 2009;26:1019-1025.

21. Sinex JA, Chapman RF. Hypoxic training methods for improving endurance exercise performance. Journal of Sport and Health Science. 2015;4:325-332.

22. Pérez-Padilla R. Population distribution residing at different altitudes: implications for hypoxemia. Archives of Medical Research. 2002 33:162-66.

23. Hirata K, Ban T, Jinnouchi $Y$, Kubo S. Echocardiographic assessment of left ventricular function and wall motion at high altitude in normal subjects. Am J Cardiol. 1991;68:1692-1697.

24. Penaloza $D$, Arias-Stella J. The heart and pulmonary circulation at high altitudes. Circulation. 2007:115:1132-1146.

25. Antezana AM, Kacimi R, Le Trong JL, Marchal M, Abousahl I, Dubray C, et al. Adrenergic status of humans during prolonged exposure to the altitude of 6,542 m. J Appl Physiol. 1994;76:1055-1059.

26. Calbet JAL. Chronic hypoxia increases blood pressure and noradrenaline spillover in healthy humans. J Physiol. 2003;551:379-386.

27. Hakim TS, Michel RP, Minami H, Chang HK. Site of pulmonary hypoxic vasoconstriction studied with arterial and venous occlusion. J Appl Physiol. 2017;54:1298-1302.
28. Sylvester JT, Shimoda LA, Aaronson PI, Ward JP. Hypoxic pulmonary vasoconstriction. Physiol Rev. 2012 92:367-520

29. Hughes JMB. Hypoxic pulmonary vasoconstriction: clinical implications. Eur Respir J. 2016;47:31-34.

30. Hoeper MM. Definition, classification, and epidemiology of pulmonary arterial hypertension. Semin Respir Crit Care Med. 2009;30:369-375.

31. http://www.who.int/news-room/fact-sheets/detail/ambient-(outdoor)-air-quality-andhealth, 2018.

32. Calderón-Garcidueñas $L$, Calderón-Garcidueñas A, Torres-Jardón $R$, Ávila-Ramírez, J, Kulesza RJ, Angiulli AD. Air pollution and your brain: what do you need to know right now. Prim Health Care Res Dev. 2015:16(4):329-345.

33. Calderón-Garcidueñas $L$, Calderón-Garcidueñas A, Torres-Jardón $R$ Ávila-Ramírez J, Kulesza RJ, Angiulli AD. Brain inflammation and Alzheimer's-like pathology in individuals exposed to severe air pollution. Toxicol Pathol. 2004:32:650-658.

34. Aire Ciudad de México. Disponible en: www.aire.gob.mx http://www.aire.CIUDAD DE MÉXICO.gob.mx/descargas/publicaciones/flippingbook/informe_ anual_calidad_aire_2017/mobile/\#p=1 Consultado el 20 de junio de 2019.

35. Kapuku G, Davis H, Choksy P, Januzzi J, Harshfield G. Brain natriuretic hormone predicts stress induced alterations in diastolic function. $\mathrm{J}$ Card Fail. 2012;18:S11-S12.

36. Choksy P, Davis HC, Januzzi J, Thayer J, Harshfield G, Robinson VJ, Kapuku GK. Brain natriuretic hormone predicts stress-induced alterations in diastolic function. Am J Med Sci. 2014:348;366-370.

37. Ohlwein S, Klümper C, Vossoughi M, Sugiri D, Stolz S, Vierkötter A, et al. Air pollution and diastolic function in elderly women-Results from the SALIA study cohort. Int J Hyg Environ Health. 2016:219:356-363.

38. Aung N, Sanghvi MM, Zemrak F, Lee AM, Cooper JA, Paiva JM, et al. Association between ambient air pollution and cardiac morpho-functional phenotypes: insights from the UK Biobank population imaging study. Circulation. 2018:138:2175-2186. 